\title{
The Effects Of Decision Framing Influences On Decision Performance
}

David Shelby Harrison (Email: davidh@usca.edu), University of South Carolina, Aiken

Sanela Porca (Email: sanelap@usca.edu), University of South Carolina, Aiken

\begin{abstract}
This study investigates the effects of two components of decision framing [commitment and verbalization] in decision optimization, and how information quality impacts framing effects on decision performance. The theory of cognitive dissonance predicts that commitment to a decision will foster insensitivity to alternative choices. We find that such bias can be beneficial in certain decision strategies, and more powerfully influential as information quality worsens. We used an interactive computer simulation to test decision framing effects in a profit optimizing business simulation and to examine the magnitude of the framing effect under varying conditions of information quality, which was proxied as cost information type (ABC: higher quality; VBC: lesser quality). The influences of these factors were tested on the profit optimizing abilities of 48 accounting majors under controlled, laboratory conditions. Results showed that framing influences improved decision-making, and the effects of framing influences were more powerful in decision environments of poorer quality information [VBC] than in higher quality decision environments $[A B C]$. Framing was most supportive of decisions when most needed, poor information environments, and not of significant influence in clearer decision environments.
\end{abstract}

\section{Introduction}

A ctivity-based costing (ABC) methods seek to more precisely identify cost relations. The value of indirect cost assignments, precise or not, is questioned by some, however (Goldratt 1984, 1994, 1999; Johnson 1992; Hiromoto 1988). Even so, ABC's popularity in the classroom and in practice is well established ${ }^{1}$. The presumption of $\mathrm{ABC}$ effectiveness lies in the rational position that better cost information triggers better decisions. Other factors, however, beyond the efficacy of information content itself can strongly influence decisions as well. Drake et al. (1999) found in an experiment using MBA students that behavioral influences on the use of ABC information had greater influence on [experimental] firm profits than the information content.

Related to the decision usefulness of any analytic tool lies the deeper human cognition issues of information receptiveness, information processing issues, and other behavioral influences. Receptiveness factors can amplify or impede decision processes and ultimately may strongly affect decision-making outcomes. Communication factors may at times be more consequential than the information content itself. Accordingly we designed a study to specifically study human reception factors as it relates to information content, in this case $\mathrm{ABC}$ information usefulness.

Our study was an interactive business simulation that examined the interacting effects of decision framing and presentation format on information usefulness. We used a controlled, experimental design targeting the [interacting] value of (1) ABC information and (2) presentation format, and (3) looking at the effects of decision framing on both. The dependent variable was business profit, as generated in the simulation. Forty-eight accounting

\footnotetext{
${ }^{1}$ Although we did not review literally all accounting texts it would be hard to imagine any managerial text without at least a significant porting of a chapter covering ABC; perhaps some do not. Management accounting research and literature abound with ABC topics. A recent search of the ABI database cited 547 articles alone.
} 
majors in their junior and senior years at a research university participated in the experiment. A mixed-factor ANOVA using repeated measures for two of the three factors was used. All experimental conditions were counterbalanced. An interactive, computer-based business simulation provided the platform for the testing.

Findings supported the notion that $\mathrm{ABC}$ information was very relevant to successful decision strategies, and interestingly, the [slightly] more complicated $\mathrm{ABC}$ information required no more decision time for participants. Decision framing affected the decision environment overall, but was especially helpful (higher simulation profits) in the non- $\mathrm{ABC}$ decision environment, having no significant impact on $\mathrm{ABC}$ information decisions.

\section{Decision Optimization: Phase One, ABC Cost Information}

Although empirical support demonstrating the value of $\mathrm{ABC}$ was a factor that clearly interested and motivated us, the issue of decision framing was our primary interest. Drake et al. (1999) found that "our experimental evidence shows that innovative activity can produce a higher or lower level of firm profit when workers have $\mathrm{ABC}$ information," they also noted that behavioral influences may override ABC benefits. Logically, our first objective was to establish that, at least within the confines of our experimental conditions, ABC had significant value, as measured by firm profits. We next looked independently at our factors of primary interest, which were two behavioral factors: (1) presentation format and (2) decision framing. The interacting effect of the combined factors completed the study. We added a second response variable to all phases of the study, decision efficiency, which we defined as decision time elapsed.

Cognitive fit theory holds that the mental representation appropriate to problem solution is a key aspect to solution efficiency (Vessey 1991, 1994). Decision outcome is influenced not only by the content of information but also by the presentation mode of the information. The manner in which the information is delivered for human cognition will influence the palatability of the information, which in turn governs its efficient use. Information that is relevant to problem solution and is cognitively compatible satisfies necessary initial steps of efficient mental processing (Vessey 1991, 1994). This process is known as decision framing. Relevant information that is suitably presented contributes to effective decision framing. Detraction from either the relevance of information or its cognitive-friendliness negatively impacts the decision framing process and the decision process suffers.

Vessey (1991) produced a pivotal paper that used a theory of cognitive fit to answer some of the seemingly conflicting graphic / tabular research results. Vessey categorized the TASK in prior presentation studies as being either spatial, symbolic, or both. Working from categorized tasks or types of decision problems, she used cognitive fit to explain the conflicting results of other research. The use of cognitive fit took some of the confusion out of the previously conflicting results. Her theory held for simple information acquisition and evaluative tasks but not for more complex analytic ones. "In effect, these studies represent decision-making tasks that are too complex to be addressed by the paradigm of cognitive fit." $(1991,232)$ Complexity was, it seemed, a confound beyond the limits of her spatial/symbolic cognitive fit theory. She defined complexity as tasks that involved a sequence of subtask decision strategies. They were not amenable to simplistic cognitive fit categorization, or to simplistic presentation fits.

Vessey viewed the mental representation process (Figure 1) as symbolizing the way working memory processes data to arrive at solutions. According to her model the characteristics of both the problem and the task reach optimal solutions when these characteristics are harmonized initially. Thus efficiency is achieved when the format of problem representation matches the process required to solve the task. If the representation and the task are not coordinated, translation of the problem representation is first required before processing can occur. This extra step confounds the representation and cognitive processes; distortion and inefficiencies result. Optimal mental representation results when data presentation and task merge without further mental processing.

Figure 1. Vessey's Model of Cognitive Fit: 


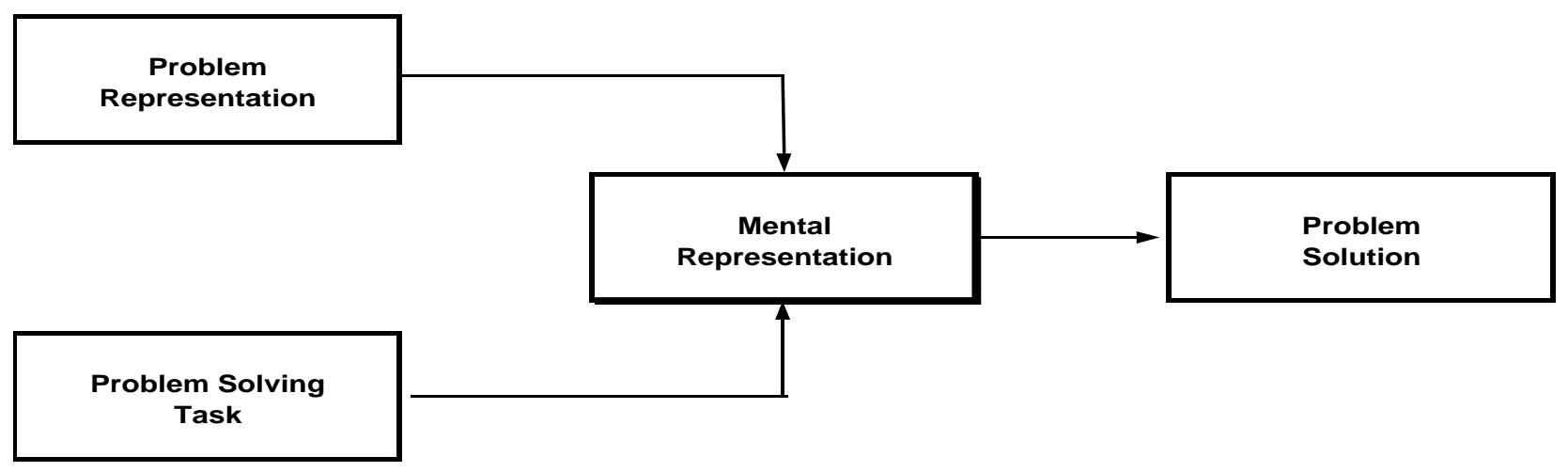

Decision Optimization: Phase Two, Decision Framing \& Bias Effects

Kahneman and Tversky (1984) show that people selectively use information in decision making. People tend to select information that conforms to their initial problem framing or their initial mental representations. Greenwald et al. (1986) refers to a classic study where people are three times more likely to properly identify blurred images given one slightly blurred picture than when people are view the picture continuously from a very blurred state to the slightly blurred state. Those with additional information were less likely to make correct identifications. The reason is premature use of that additional information. The premature decision, based on poor data, interfered with subsequent effective interpretation of more precise information. That such bias may have stronger effects in the presence of more accurate information $(\mathrm{ABC})$ is an interactive response we wanted to examine in our study.

Bias can also be a positive influence. If prior experience is relevant to present decision circumstances then this process defines the elements of productive decision-making. Bias provides, sometimes useful, initial framing in decision-making. While such framing may stifle creativity, creativity does not always lead to the best or most efficient decision-making. Framing bias here may stifle creative approaches but may provide useful direction and assist in forming productive strategies.

Vessey $(1991,1994)$ reminds us that cognitive fit is most influential as fit strengthens. Objectively ABC should provide more accurate decision information. We extend Vessey's theory to ABC by hypothesizing that framing bias will have less effect on the cognitive fit of $\mathrm{ABC}$ better than non- $\mathrm{ABC}$ information. Non- $\mathrm{ABC}$, traditional-costing (TC) information is presented as direct labor dollar cost allocations, as is common in single cost driver industrial applications. The noise from the less accurate TC information is hypothesized to impede the cognitive fit process and provide more resistance to effective decision-making. The cognitive fit realization process in the more complex situation that includes both information content (ABC / TC) and bias should be most influenced by the presence of the assumed weaker, less precise TC information. Bias should be a stronger influence in the TC environment.

Decision strategies in static decision environments that use consistent approaches (bias factor) will benefit as the incongruence of the task and information increases. The more chaotic TC information will lend itself to positive biasing effects. TC decision feedback is somewhat "off-target." It is less easily interpreted into solution possibilities. In such decision situations framing incentives that reinforce bias influences should be effective for both $\mathrm{ABC}$ and $\mathrm{TC}$, but provide more positive help to the TC conditions. 
The "less is more" paradox fits well with the theory of information overload (Vessey 1994) and cognitive dissonance. Bias or framing may serve to reduce complexity and streamline decisions. The influences of some factors change depending on the dynamic influences of other factors. That is, the level of diminishing marginal returns for complexity will vary dependent on the strength of bias and again dependent of the mental image that is effected by various presentation formats. The level of bias or presentation format may affect the point of diminishing returns for the content factor as well. This underscores the importance of the interactions among these factors, and is the reason that they were selected: they are hypothesized to have such interactions.

To operationalize the research objectives, presentation issues are grounded in the objectively dichotomous graph and table input variables. A workable proxy for framing bias is achieved by using performance incentives. The experimental set-up moved through three levels of decision influence, from the concrete to the abstract. First, the obvious influence is the pertinence or face value of the information alone. Next is the presentation of that information and finally the pre-conditioning of the decision user.

\section{Hypotheses Development}

The primary, but less exciting, research question is simple: Does ABC work? Firm profits and decision efficiency (decision time elapsed) are the response variables. As noted above however, beyond the simple "does $\mathrm{ABC}$ work" issue are our real questions of interest: the effects of framing bias and presentation format on the decision result and process. We use six hypotheses to test the main effects and two-way interactions for each of the two response variables ${ }^{2}$. To simplify the discussion of hypotheses, the six hypotheses for each response variable (profits and time) are presented as one set of six.

The main effect hypotheses are straightforward:

H\#1: $\quad$ ABC information provides better information for decision making than traditional costing methods (TC).

H\#2: The format of information presentation, spatial or symbolic, will have an effect on decision making.

H\#3: $\quad$ The presence of framing bias will have a positive effect on decision making.

$\mathrm{ABC}$ information is more accurate, permitting more straightforward analyses. TC information contains noise that confounds analysis. TC information clouding interrupts efficient mental representation. The interaction of content and presentation should show different responses as each is varied with the other. "Cognitive cost" should be different between these two factors. $\mathrm{ABC}$ information may have the most direct decision representation in the simplest of presentation modes but be less valuable as presentation mode changes. The effect on TC information may be similar but of greater magnitude as presentation changes. This is consistent with Vessey's $(1991,1994)$ mental representation, framing, and cognitive fit theories, Benbasat and Dexter's (1985) information overload theory, Davis' (1989) cognitive efficiency theory and Jarvenpaa's (1989) cognitive cost theories.

The interaction hypotheses follow:

H\#4: Presentation format will affect information processing differently depending on the congruence of the information with the problem solution (ABC vs. TC).

Framing bias should be more helpful in deciphering the less accurate TC information than it will for the $\mathrm{ABC}$ information. Subjects are likely to be more prone to inconsistent behavior given the confusing TC data. Framing should be of the most benefit in the cluttered environment. The static, repetitive nature of the decision

\footnotetext{
${ }^{2}$ We did not hypothesize the three-way interaction as it presented relations about which we had little confidence.
} 
environment encourages the discipline that framing adds to the analytic process. Framing bias should aid in providing a level of reference or consistency to help in analyzing the less relevant and less accurate TC feedback. The more relevant and accurate $\mathrm{ABC}$ information is not expected to benefit as much from framing. While framing may be beneficial to both $\mathrm{ABC}$ and $\mathrm{TC}$, it should be significantly more helpful to TC. The "cleaner" cognitive fit provided by $\mathrm{ABC}$ information is expected to be less affected by the positive influence of decision framing.

H\#5: $\quad$ Framing bias will have a more positive effect on $\mathrm{TC}$ decision making than on $\mathrm{ABC}$ decision making.

Spatially oriented subjects may utilize framing biases more readily given complex graphic visualizations than subjects for whom complex visualizations are more challenging to process. Presumably framing will have a greater magnitude in effect for the mental representations afforded by visual graphics versus numeric listings. The benefit to this static analytic problem of repeated trials should be greater for one visualization than another:

H\#6: $\quad$ Presentation format will affect subject performance differently depending on the presence of framing bias.

\section{Experimental Method And Design}

The hypotheses were tested using a $2 \mathrm{X} 2 \mathrm{X} 2$ mixed-factor experimental design structured for ANOVA ${ }^{3}$. The primary experimental condition of the study, $\mathrm{ABC}$ information, was between-subjects. The other two conditions, presentation and bias, were within-subjects. The mixed-factor design divided the 48 participants into two groups, $\mathrm{ABC}$ information only and TC information only. Within each group participants repeated the experiment four times, representing the four possible combinations of the two crossed conditions (presentation and bias). Crossed conditions were completely counterbalanced.

A computerized business simulation was written that incorporated the three experimental conditions of interest. The simulation was a model of a profit-oriented business in which the participants' objective was to maximize profits. Participants made product volume decisions in the simulation to maximize profits. They were offered incentives to maximize their game performances relative to other players. [Real money, with an expected value of $\$ 25$ per player, a range of $\$ 5$ to $\$ 100$, and extra credit points in an accounting course.] The game was completely automated and player-interactive.

Players were told they were in the business of making baseball equipment. They had four baseball products [bats, balls, gloves, and pitching machines] for which they set production levels, which could vary from zero to large numbers of units. Demand was infinite and prices were fixed. Costs were governed by eight production functions, six of which were overhead. Half of the overhead functions were complex, non-linear functions, which were further complicated by volume interrelationships; production of one product affected the costs of other products. The cost structure of the game mimicked real business to the extent practical.

\section{Experimental Conditions}

Factor One, availability of $\mathrm{ABC}$ information was operationalized as a dichotomous variable where $\mathrm{ABC}$ information was either available or not. For $\mathrm{ABC}$ participants the cost information was displayed in eight lines of information: material, direct labor, and six overhead costs. The non- $\mathrm{ABC}$, TC players got three lines of cost information: material, direct labor, and one overhead cost line. The ABC costs were assigned based on cost pool activities. TC costs were assigned on a direct labor dollar basis. Total overhead cost for all production combined was identical regardless of $\mathrm{ABC} / \mathrm{TC}$ cost assignment. Cost assignment among the four products were, however, not

\footnotetext{
${ }^{3}$ As was hypothesized and found to be true, the response variables were highly correlated. We ran MANOVA analyses, but they provided no new information or insights beyond that obtained from the standalone ANOVA's.
} 
identical. $\mathrm{ABC}$ assignments were more accurate. Regardless of cost assignment, total business costs and profitability were identical given identical production input decisions.

Factor Two, presentation, was a within-subjects variable. Summary financials were given numerically regardless of the presentation condition, but the detailed product cost and profitability information (ABC or TC) was given either in graphic or tabular format. The graphs were simple bar charts.

Factor Three, framing bias, was also within-subjects. Bias was injected into two of the four games that participants played. The operational design of the framing condition was simple: two games included bias and two did not. While graphs and $\mathrm{ABC}$ information were simple categorical conditions that were easily operationalized, the introduction of bias was more complex ${ }^{4}$. To establish decision bias additional monetary incentives were used as a means to force a 'decision framing effect.' Players assigned to this bias condition were told that if their verbalized strategy was correct and they stayed with it that they would receive an additional $\$ 25$ bonus for that game. They were also told that in fact if they met these conditions it would probably turn out that they had the best results in their group of eight so they would win the $\$ 100$ top prize as well. The players that were not assigned the decision framing condition were told to verbalize their strategy as well but were offered no additional monetary incentive. Wicklund and Brehm (1976) and Church (1990) concluded that decision bias is stronger when people verbally commit to a position and when they choose that position themselves. Accordingly players were instructed to input their decision strategies about halfway through each game. The bonus serves to intensify the bias effect and thereby differentiate the bias group.

\section{Results}

The $\mathrm{ABC}$ condition and the framing bias condition influenced profits significantly. The $\mathrm{ABC}$ factor had a p-value of .002 , which supports the basic premise of the research that $A B C$ provides relevant decision-making information. Profitability response variable results were also significant for the framing/bias condition and the $\mathrm{ABC} / \mathrm{Bias}$ interaction. The presentation condition was not significant for the profit response variable. Presentation did, however, significantly affect decision time. ANOVA results are shown on Table 1.

Response variability for profits was large, as evidenced by large mean squares. The large variances account for the reason that some seemingly large differences in average response [Table 2] were not significant. Other significant results, showing different profits for $\mathrm{ABC}$, bias, and the $\mathrm{ABC} / \mathrm{Bias}$ interaction, had no discernable time differences. This particular combination of profitability results for all factors except presentation, and timing results for presentation alone, and none for the other factors provides support for the overall design. A different combination of results might have implied that the model simply did not pick up some effects adequately because of poor design. These results, one pattern of effects for one response variable and a complete reversal of effects for the other response variable, indicates the model differentiated well. All of the significant differences appear to represent meaningful differences. For example, Table 2 shows that the significant time differences for presentation modes were greater than ten percent and the significant profitability differences were hundreds of thousands of dollars (over an average profitability range of, at most $\$ 1.2$ million). Table 2 presents the average profitability and elapsed time results for all significant differences. Player response ranges, and accordingly, associated variances were large. Hence, significant differences tended to be meaningful on a practical as well as statistical level.

\footnotetext{
${ }^{4}$ We originally sought to operationalize a form of confirmation bias. Our design would have included a more dynamic decision environment and confirmation bias would have had negative effects (preliminary decisions based on incomplete information negatively affecting subsequent decision behavior). This operationalization simply proved too difficult to adequately control. We changed the decision environment to static and bias moved from a decision detractor to a positive or decision-friendly effect by adding focus to otherwise chaotic conditions.
} 


\section{TABle 1 AnOVa Results}

*Significant Differences (@ P <.05) Are Shown In Bold

\begin{tabular}{|c|c|c|c|c|c|}
\hline Hypothesized Effect & Response & Df & $\begin{array}{c}\text { Mean } \\
\text { Squares(*) }\end{array}$ & F Value & P Value \\
\hline \#1: Info. Content -- ABC/TC & $\begin{array}{l}\text { Profits } \\
\text { Time }\end{array}$ & $\begin{array}{l}1 \\
1\end{array}$ & $\begin{array}{c}7.0 \mathbf{E}+13 \\
1.75\end{array}$ & $\begin{array}{c}\mathbf{1 0 . 4 5} \\
0.03\end{array}$ & $\begin{array}{c}\mathbf{0 . 0 0 2} * \\
0.866\end{array}$ \\
\hline $\begin{array}{l}\text { \#2: Presentation -- } \\
\text { Graph/Table }\end{array}$ & $\begin{array}{l}\text { Profits } \\
\text { Time }\end{array}$ & $\begin{array}{l}1 \\
1\end{array}$ & $\begin{array}{c}6.5 \mathrm{E}+11 \\
\mathbf{1 2 7}\end{array}$ & $\begin{array}{l}0.08 \\
\mathbf{5 . 0 6}\end{array}$ & $\begin{array}{c}0.778 \\
\mathbf{0 . 0 2 9} *\end{array}$ \\
\hline $\begin{array}{l}\text { \#3: Framing Bias - } \\
\text { Bias/None }\end{array}$ & $\begin{array}{l}\text { Profits } \\
\text { Time }\end{array}$ & $\begin{array}{l}1 \\
1\end{array}$ & $\begin{array}{c}\text { 6.7 E+12 } \\
8.49\end{array}$ & $\begin{array}{l}6.15 \\
1.65\end{array}$ & $\begin{array}{c}\mathbf{0 . 0 1 7 *} \\
0.206\end{array}$ \\
\hline $\begin{array}{l}\text { \#4: Info. Content \& } \\
\quad \text { Presentation Interaction }\end{array}$ & $\begin{array}{l}\text { Profits } \\
\text { Time }\end{array}$ & $\begin{array}{l}1 \\
1\end{array}$ & $\begin{array}{c}7.5 \mathrm{E}+11 \\
1.86\end{array}$ & $\begin{array}{l}0.09 \\
0.07\end{array}$ & $\begin{array}{l}0.763 \\
0.787\end{array}$ \\
\hline $\begin{array}{r}\text { \#5: Info. Content \& Framing } \\
\text { Interaction }\end{array}$ & $\begin{array}{l}\text { Profits } \\
\text { Time }\end{array}$ & $\begin{array}{l}1 \\
1\end{array}$ & $\begin{array}{c}\mathbf{5 . 7} \mathbf{E}+\mathbf{1 2} \\
3.68\end{array}$ & $\begin{array}{l}\mathbf{5 . 1 8} \\
0.71\end{array}$ & $\begin{array}{c}\mathbf{0 . 0 2 8} * \\
0.403\end{array}$ \\
\hline $\begin{array}{r}\text { \#6: Presentation \& Framing } \\
\text { Interaction }\end{array}$ & $\begin{array}{l}\text { Profits } \\
\text { Time }\end{array}$ & $\begin{array}{l}1 \\
1\end{array}$ & $\begin{array}{c}7.3 \mathrm{E}+11 \\
4.5\end{array}$ & $\begin{array}{l}0.49 \\
0.43\end{array}$ & $\begin{array}{l}0.489 \\
0.514\end{array}$ \\
\hline
\end{tabular}

TABle 2 AVERAge ReSults by EXPERIMENTAL Conditions

(See Table 1 for Mean Squares and Significance Levels)

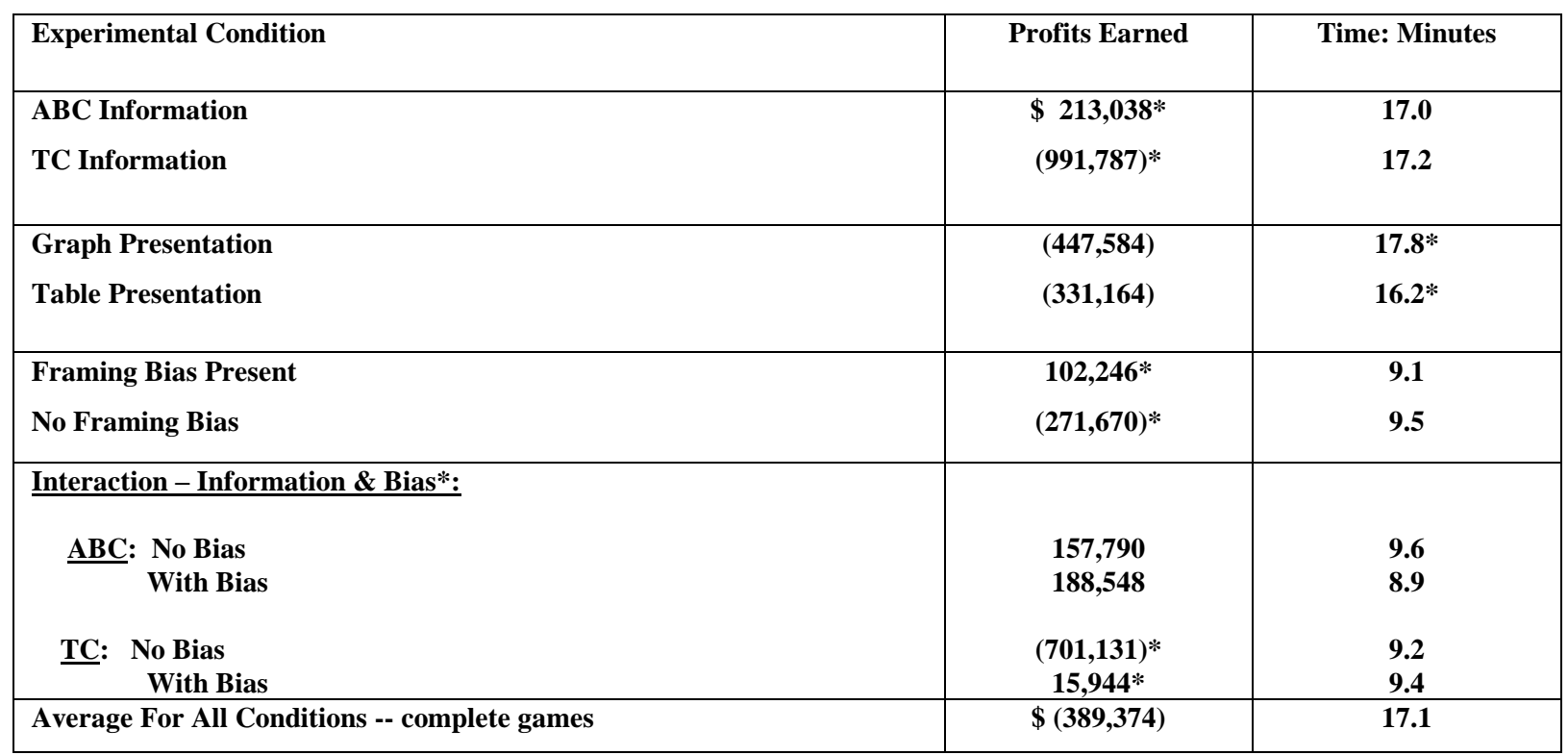

Averages are calculated based on full game results (years 2 - 12 less worst) except for Bias Conditions and Interactions which covered years 6-12 less worst.

*Denotes significant effect -- (@ 5\%);

[t-test on ABC interaction component (profits), $p=.38$;

$t$-test on TC interaction component (profits), $p=.034$;

t-tests for time showed no significance for any of the interaction components. 
The game was discriminating in awarding profits, but had low tolerance for inputs outside its optimal operating ranges. Accordingly losses were common and sometimes high. We believed that this somewhat narrow range of profitability approximated true industry operating ranges.

\section{Testing of ABC Information Value}

As predicted players had better simulation profits when provided with $\mathrm{ABC}$ information than when they were given TC information. Average profits for the ABC players were \$213,038; the TC players lost an average of $\$ 991,787$. These differences were significant at $\mathrm{p}=0.002$.

It took essentially the same time to make decisions. This lack of difference could be a fault of the model design or it could be a result of offsetting influences. We expected $\mathrm{ABC}$ information to take more time to process. Average game time for $\mathrm{ABC}$ was 16.97 minutes; average time for the TC game was 17.16 minutes.

\section{Decision Framing Bias: Present or Not}

The decision framing condition was based on sound theoretic hypotheses but was an ambitious (and perhaps risky) operationalization. It was therefore rewarding to find that framing significantly affected the quality of decisions made (profits). Importantly, the direction of difference held and the positive interaction effects (discussed below) also supported the theory that predicted the results obtained.

Players that were influenced to frame decisions made better use of the game information and made better decisions. It took them no longer to make these better decisions. The lack of elapsed time differences is important. It gives additional theoretic support for the hypothesized framing results, as it did for information content (ABC/TC). Since decision time was the same for the framing and non-framing condition and all other factors were controlled at the same levels, the significant result can be attributed to differences in the framing condition.

The positively framed players made average profits of $\$ 102,246$. The uninfluenced players lost $\$ 271,670$. It took 9.08 minutes for the positively influenced players to make their decisions versus 9.50 minutes for the uninfluenced. Execution of the framing condition included a monetary incentive that was not offered to the "nonframed" players. This situation invites the speculation that observed differences could be the result of motivational changes resulting from differing monetary incentives and not because of the desired bias condition. Had the profitability differences been due to monetary incentives and motivation, however, one would expect that the financial incentive would have similarly motivated a more serious game approach that would have resulted in those players spending more time attempting optimization. That did not occur.

If we take the position that time spent is a reasonable proxy for motivation, then we can infer that players with the framing incentive were no more motivated that the non-incentive players. Further, the variances for the framing incentive group were much smaller than the group without the incentive. Standard deviations were $\$$ 202,337 for the incentive group versus $\$ 1,654,584$ for the non-incentive group. Smaller variances support successful implementation of the framing bias. Framing was designed to influence players to adhere to preliminary strategies in working toward final solutions. The fact that their decisions were better, their variances smaller, yet their times were the same provides further evidence of successful framing operationalization.

\section{Interactions}

Main effect analyses showed strong, favorable profitability effects for $\mathrm{ABC}$ information and framing bias. The interaction between theses two factors was also significant. Decision framing helped the TC information group substantially more than framing helped the $\mathrm{ABC}$ information group.

These stronger TC Bias effects were predicted. Although the profitability and cost functions changed from game to game, within each game (12 years of play) these functions remained the same. Successful strategies were 
those that used yearly feedback to understand overhead cost functions. Framing was valuable as it added focus to the process. In the $\mathrm{ABC}$ environment that focus was of some incremental value (average profits moved from $\$ 157,790$ to $\$ 188,548$ under the added influence of bias) but not substantially so. In the more chaotic, less predictable TC environment, players had a more difficult time understanding overhead cost behavior. In this situation the focus that the framing influence brought to the players analysis was very helpful. Average profits went from a loss of $\$ 701,131$ to a gain of $\$ 15,944$.

Again, interaction decision times elapsed did not vary significantly from condition to condition. As with framing as an individual influence, the lack of significant time differences adds support to the validity of the framing operationalization for the interaction effects. Because decision times were essentially equal from condition to condition it seems that players were similarly motivated. It was the decision information and framing that appeared to directly affect decision performance, not motivational differences. Bias framed the decision but did not seem to add much motivational incentive (as measured in time elapsed). The bias/framing condition was introduced after year five. The average times to complete games 6 - 12 (less the longest) were from 8.9 minutes to 9.6 minutes. Interestingly in both the $\mathrm{ABC}$ and $\mathrm{TC}$ cases the non-bias condition spent more time (although not significantly more) on play, again at least intuitively supporting the success of the framing condition versus mere motivational proxies. The other two interacting conditions, $\mathrm{ABC}$ / Presentation, and Bias / Presentation, showed no significant profitability or time differences.

\section{Conclusion}

This study provides empirical evidence that $\mathrm{ABC}$ information is of value in making profit-oriented decisions. Importantly, although $\mathrm{ABC}$ information is more detailed and complex it does not appear to take more analytic time in productive decision-making. The empirical support this study offers compliments the business literature.

The finding that framing bias, as defined in this study, had the hypothesized favorable influences broadens our understanding of the importance of mental representation and decision processes. It was particularly interesting that bias had the most beneficial profit influences under the more chaotic decision environment offered by the TC condition. The interaction effect supports the hypothesized main effect conclusions for both $A B C$ and bias. In effect focus is most beneficial in a less structured environment, and $A B C$ information is effective enough that even positive focusing influences need not have that much impact. As a result we have a greater appreciation for how accounting $\mathrm{ABC}$ information can be most productively utilized.

Intuitively $\mathrm{ABC}$ appears unchallengeable in providing more relevant information from which important, profit-dependent decisions can be made. To date descriptive research such as the surveys cited above seem to favor $A B C$. Yet, the $A B C$ backlash remains. While this study may not convince the critics, we can at least say that under conditions uncomplicated by the reality of the real business world, human cognition favors $\mathrm{ABC}$ information and that it benefits from framing bias. Related decisions benefit most with less reliable cost feedback (non-ABC information), and that humans take longer to productively decipher graphic information in this setting than tabular information.

In addition to exploring the decision framing and presentation design issues further, future research could explore group decision dynamics by measuring the quality and time differences for groups playing the simulation. We believe time differences would be of special interest for such group settings. Further study could pursue the topic of mental representations. The effect of confirmation bias on mental representations and decision making could be explored by extending the simulation to force preliminary decisions on participants that are given inadequate or misleading information. 


\section{References}

1. Benbasat, I. and A. S. Dexter. 1985. "An experimental evaluation of graphical and color enhanced information presentation." Management Science, Vol 31: No. 11, (November): 1348-1364.

2. ----- and ------. 1986. "An investigation of the effectiveness of color and graphic information presentation under varying time constraints." MIS Quarterly (March): 59-81.

3. Church, B.K. 1990. "Auditors' use of confirmatory processes." Journal of Accounting Literature: 81 122.

4. Davis, L.R. 1989. "Report format and the decision maker's task: an experimental investigation." Accounting, Organizations and Society: 495 - 508.

5. ----- and S. L. Jarvenpaa. 1989. "Graphical presentation of accounting data for financial forecasting: an experimental investigation." Accounting, Organizations and Society Vol. 14, No. 5/6: 509 - 525.

6. Drake, A.R., S.F. Haka and S.P. Ravenscroft. 1999. "Cost structure and incentive structure effects on innovation, efficiency and profitability in teams." Accounting Review Vol. 74, No. 3: 323-345.

7. Goldratt, E. M. 1984. The Goal. North River Press, New York

8. $\quad$-----. 1994. It's Not Luck. North River Press, New York

9. $\quad$----. 1999. Satellite Series on Management, Netherlands

10. Greenwald, A.G., M.R. Leippe, A.R. Pratkanis and M.H. Baumgardner. 1986. "Under what conditions does theory obstruct research progress?" Psychological Review: 216 - 228.

11. Hiromoto, T. 1988. "Another hidden edge -- Japanese management accounting." Harvard Business Review. 66 No. 4, July-August.

12. Johnson, H.T. 1992. "It's time to stop overselling activity-based concepts." Management Accounting: 2635

13. Jarvenpaa, S. L. 1989. "The effect of task demands and graphical format on information processing strategies." Management Science Vol. 35, No. 3 (March): 285 - 303.

14. Kahneman, D.and A.Tversky. 1984. "Choices, values \& frames." American Psychologist: 341-350.

15. Vessey, I. 1991. "Cognitive fit: a theory-based analysis of the graphs versus tables literature." Decision Sciences: 22 (2) 219 - 241.

16. -----. 1994. "The effect of information presentation on decision making: a cost-benefit analysis." Information and Management. 